\title{
TRES SIGLOS EN LA HISTORIA DE UNA PARROQUIA MADRE: LA ASUNCIÓN DE AGUASCALIENTES
}

JESÚS ANTONIO DE LA TORRE RANGEL

Departamento de Derecho/UAA

José Antonio Gutiérrez G., Historia de la Iglesia Católica en Aguascalientes, Volumen I: Parroquia de la Asunción de Aguascalientes, Aguascalientes, Universidad Autónoma de Aguascalientes/Obispado de Aguascalientes/ Universidad de Guadalajara, 1999, 456 pp.

\section{INTRODUCCIÓN}

La diócesis de Aguascalientes fue erigida por el decreto consistorial Apostólica Sede del Papa León XIII, de fecha 27 de agosto de 1899, desmembrándola de la arquidiócesis de Guadalajara. Dice el doctor José Antonio Gutiérrez que el presbítero Mauricio M. López, precisamente párroco de la Asunción, tuvo la alegría de "recibir la noticia de ese notable acontecimiento, y asistió al acto ejecutorio de creación, efectuado por el visitador apostólico, Mons. D. Nicolás Averardi el 3 de diciembre de 1899." (p. 383)
Es importante que en el centenario del nacimiento de la diócesis de Aguascalientes, salga a la luz pública este trabajo. Saludamos con interés la publicación del libro, que como bien dice el autor "es el primero en su género que historía integralmente la vida de la parroquia y que rescata el abundante material existente para dar a conocer la institución." (p. 13)

\section{LA ESTRUCTURA DEL LIBRO}

El título de la obra no deja lugar a dudas sobre su contenido: se trata de una historia de la parroquia de la Asunción de Aguascalientes, hasta antes de la erección de la diócesis, con la pretensión de ser sólo la primera parte de una obra mayor que sería la de la iglesia diocesana toda. Su objetivo ha sido, dice el autor, "analizar el actuar del hombre, eclesiástico o laico, que gestó esta historia particular; su 
grado de participación en el entorno y su relación con las diversas instituciones eclesiales. Es la perspectiva del hombre y las instituciones desde la evangelización hasta 1899." (p. 13).

El libro está dividido en cinco partes, constituidas por una breve introducción y cuatro grandes capítulos. El primero de ellos to ha titulado "Descubrimiento y conquista material y espiritual", tratándose de un capítulo que pretende establecer los antecedentes históricos nacionales (novohispanos) y regionales (neogallegos) del nacimiento de Aguascalientes como villa y de la Parroquia de la Asunción como centro religioso y eclesial, así como el momento coyuntural en que se da la fundación de una y otra. El segundo capítulo se titula "Parroquia de Aguascalientes. Siglo XVII", y trata de la fundación de Aguascalientes y su desarrollo histórico en el siglo XVII, así como de la erección de la Parroquia y su vida en esa centuria. El tercer capítulo ha sido denominado "La Parroquia de Aguascalientes en el siglo XVIII"; en él se vuelve a establecer el marco histórico general y de Aguascalientes en particular, y se hace historia de una parroquia que llega al máximo esplendor sobre todo por lo que se refiere a la obra material, por la fábrica de los más importantes de nuestros bellísimos templos: el templo parroquial -hoy Catedral-, la Merced -hoy El Rosario-, San Marcos, San José, El Encino, Guadalupe, Tercera Orden de San Francisco y Camarín de San Diego y San Juan Nepomuceno. El cuarto y último capítulo se titula "La Parroquia en el Siglo XIX"; en él se nos ofrece el marco histórico nacional y local de esa tan conflictiva centuria y en particular tan dura y difícil para la Iglesia en virtud de la Reforma.

En todos y cada uno de los capítulos se habla tanto de la persona como gobierno, de los obispos diocesanos de Guadalajara y su relación concreta con la parroquia aguascalentense; así conocimos más de cerca a un Gómez de Mendiola o a un Ruiz de Cabañas, por mencionar a dos; también se hace historia del carácter, virtudes y defectos, así como de la labor administrativa y pastoral de cada uno de los párrocos de la Asunción.

\section{LOS MÉRITOS DE LA OBRA}

Desde mi punto de vista, el más grande mérito del libro que comentamos es la inmensa cantidad de datos que aporta para el conocimiento de nuestra historia diocesana y de la parroquia de la Asunción en particular. Todo ese extraordinario cúmulo de datos que el Dr. Gutiérrez nos hace accesibles en su libro, han sido obtenidos de su paciente y cuidadoso traba- 
jo en varios archivos, tales como los de la Mitra de Aguascalientes, la Mitra de Guadalajara, el de Instrumentos Públicos de Guadalajara, el de la Real Audiencia de Nueva Galicia, el Histórico del Estado de Aguascalientes, así como el de las parróquias más antiguas y que hoy pertenecen a la jurisdicción diocesana de Aguascalientes, entre otros.

El Dr. Gutiérrez nos da a conocer desde cuestiones básicas como el nacimiento mismo de la parroquia de Aguascalientes a principios del siglo XVII, en el episcopado del ilustre don Alonso de la Mota y Escobar (p. 127), siendo probablemente su primer párroco Bartolomé Rodríguez de la Vera (p. 132); nos proporciona interesantísimos datos sobre las órdenes religiosas que se establecieron en la villa de la Asunción, tales como carmelitas, franciscanos dieguinos, mercedarios y su escuela y los juaninos y su hospital; y llega a darnos noticia hasta de cuestiones relacionadas con el gasto de cera en las ceremonias religiosas y la colocación de imágenes en los templos.

Esos datos nos permiten saber que el cabildo municipal de la villa de Aguascalientes declaró patrón de la ciudad a San Francisco de Asís con autorizaciones eclesiásticas (pp. 205, 210 y 218).

El autor dedica muchas páginas a exaltar la figura y la gran obra material y administrativa de dos párrocos del siglo XVIII aguascalentense: los ilustres Manuel Colón de Larreátegui (1733-1758) y Mateo José de Arteaga (1761 y 1768). Esta parte del libro es muy importante ya que constituye la base para la afirmación del Dr. Gutiérrez en el sentido de que "la Iglesia de Aguascalientes contribuyó, en el siglo XVIII, a crear una arquitectura religiosa todavía no superada; y que contara con la instrucción gratuita y con un sistema de servicios caritativos dignos de la mejor ciudad." (p. 209).

Otro aporte de este libro es que proporciona más conocimientos de los que teníamos sobre el Aguascalientes y su entorno geopolítico del siglo XVI. Incluso da detalles de pobladores o personas con mercedes de tierra que no habían mencionado ni Agustín R. González, ${ }^{1}$ ni Carlos Salas López ${ }^{2}$ y ni el mismo don Alejandro Topete del Valle en sus diversos trabajos. ${ }^{3}$ El autor incluye una cita de

1 Agustín R. González, Historia del Estado de Aguascalientes, Editado e Impreso por Francisco Antúnez, Aguascalientes, 1974.

2 Carlos Salas López, Carlos, Para la Historia de Aguascalientes, Folletín de "La Prensa", Aguascalientes, 1919.

3 Alejandro Topete del Valle, Aguascalientes. Guía para visitar la ciudad y el Estado, Edición del autor, Aguascalientes, 1973; y "Pequeña Visión Histórica de Aguascalientes", en Aries 133, Aguascalientes, abril de 1988. 
McBride que es muy importante, porque nos hace tomar conciencia de cómo se ha formado y es la gente de nuestra región:

Los primeros propietarios de las tierras en la región fueron agricultores procedentes de España, de los campos agrícolas comunales de Aragón y Castilla... Fueron realmente granjeros que prefirieron asentarse en pequeñas propiedades (dotaciones) para vivir en forma primitiva (sic) como sus vecinos los indígenas. Cuando las condiciones permitían se originaba el mestizaje; cuando no, la etnia española se conservó con poca o ninguna mezcla; lo último constituyó la generalidad..., y constituyó el único ejemplo en el Nuevo Mundo de españoles que vinieron a ser reales colonizadores y que cultivaron la tierra con sus propias manos. (págs. 67 y 68).

El Dr. Gutiérrez nos mete de lleno, en su libro, en la fascinante historia regional del siglo XVI. Tierra de conquista, tierra de guerra; región de mineros y agricultores; zona de misión, de inicio de la evangelización. Hace referencias constantes a la Guerra de Mixtón, hito histórico en donde los cazcanes pusieron en entredicho la Conquista. Cedo a la tentación de citar a Pedro Reygadas:

Levantaron al nuevo Dios pirámides de miedo que se veían a lo lejos y se miró entonces la que llamaron catedral de Guadalajara y en adelante me llamaron Santiago Ycpac de la Nueva Galicia, aunque antes el capitán Nuño de Guzmán quiso nombrar mi región Nueva Castilla de la Mayor España; pero no nombraron capitanes donde reyes gobiernan y la corona impuso su nombre; Nuevo Reino de la Galicia y su ciudad capital Compostela, creados por Dios para gloria y uso de sus majestades católicas. Y yo quedé finalmente en la frontera, mitad Nueva Galicia y mitad Nueva España, pero en verdad ninguna, porque yo soy un hilo de agua, hilo de lágrimas que corren -y es que a veces, Ventura, la historia es un río de penas-.

Los conquistadores vencieron a los indios, escribieron la esclavitud y declararon a su majestad y al papa que eran hombres los indios. Y los cazcanes les clavaron la lanza, les dieron la vuelta, sintieron la blandura de su carne y probaron su sangre salada y supieron también que eran hombres, y los conquistadores que quedaron vivos después de la rebelión de la Gran Cazcana regresaron a su tierra extraviando caminos después de haber perdido las esperanzas de hallar cerros de oro, Potosíes, Dorados y Guanajuatos que brillasen a la distancia con el resplandor mineral - ¿y es que, verdad, Ventura, que la historia del oro se paga a veces con historias de sangre?--.4

Un tercer aporte de la obra que comentamos es la relación histórica que hace de la Iglesia local en el siglo XIX, y en concreto lo referente a la Reforma. Co-

4 Pedro Reygadas, Cenizas. Ed. Práxis. México, 1997. págs. 85 y 86. 
nocíamos la actuación de las autoridades y de los grupos liberales como los famosos Rojos de Estevan Ávila, por las obras de los historiadores locales como Agustín R. González, Jesús Gómez Serrano y Enrique Rodríguez Varela, ${ }^{6}$ pero no se habían historiado desde la Iglesia esos cruciales años de la Reforma. Ahora tenemos una visión más completa del período y la posibilidad de, como se dice coloquialmente, "ir atando cabos", para conocer más nuestra historia en general y de esa conflictiva etapa en particular. Así, el Dr. Gutiérrez, entre otras cosas, nos narra las dificultades, primero del cura párroco de la Asunción Antonio Vélez Valle, del cual dice "fiel custodio de los bienes de la Iglesia, y más de una vez se extralimitó en su defensa; por lo que sufrió rudos ataques del grupo local liberal rojo." (p. 360); después nos cuenta que don Miguel Frutos, encargado de la parroquia, "continuó afrontando los serios problemas derivados de Constitución y Leyes de Reforma." (p. 361); y más adelante nos da a conocer aspectos interesantes del magistrado del Supremo tribunal de Justicia don Manuel Alonso, del cual teníamos noticia por Agustín R. González. Esto para mencionar sólo unos aspectos del tratamiento que de ese período hace el autor.

Un cuarto aporte de la obra lo constituye la narración de varios hechos intere- santes y otros curiosos. Por ejemplo, nos habla de aquel grave y bochornoso incidente de 1671, en que el cura párroco de Aguascalientes Nicolás de Echerreaga se ve envuelto en el lío del asesinato de la india Magdalena del Pueblo de San Marcos; caso lleno de incidencias, entre las cuales está la disputa de la jurisdicción real frente al derecho de asilo argumentado por los frailes del convento de San Diego. Esta historia la conocíamos por Vicent Ribes Iborra, historiador valenciano que reconstruyó esta historia con documentos del Archivo General de Indias de Sevilla; ${ }^{7}$ la versión del Dr. Gutiérrez está basada en documentos de la biblioteca Ignacio Dávila Garibi de la Cámara de Comercio de Guadalajara.

El autor también nos narra, en el rubro de cuestiones curiosas, que el obispo de Guadalajara Diego Aranda y Carpinteiro -según refiere don Agustín Rivera-, "tenía la costumbre de nombrar capellanes y

5 A. R. González. Ob. cit. cap. XX.

6 Jesús Gómez Serrano (con la colaboración de Enrique Rodríguez Varela) Aguascalientes en la Historia (1786-1920), tomo I, vol. I. México, Góbierno del Estado de Aguascalientes e Instituto de Investigaciones Dr. José María Luis Mora, 1988.

7 Vicent Ribes Iborra, "Cuando el Diablo señoreó Aguascalientes", en Espacios, núm. 11, Aguascalientes, septiembre-octubre de 1993. págs. 27-32 
confesores de monjas a viudos con hijos que se habían ordenado y eran sacerdotes virtuosos, porque, decía: 'los viudos conocen mejor el genio de las mujeres que los que no han sido casados'." (p. 320)

\section{ALGUNOS APUNTAMIENTOS CRÍTICOS}

A continuación voy a hacer crítica de algunos aspectos puntuales del texto que nos ocupa, especialmente desde la óptica de la historia del derecho, que es una materia que he estudiado. Lo hago como académico en búsqueda de la verdad.

El Dr. Gutiérrez, al mencionar a Nuño Beltrán de Guzmán en relación con la primera audiencia, la cual presidió, y en relación también con su enemigo Hernán Cortés, dice: "Cortés fue exonerado de cuanto se le acusaba y confirmado en el gobierno.” (p. 30). Hernán Cortés una vez que se le sujetó a juicio de residencia y al través del cual se le hicieron varias acusaciones, nunca fue exonerado, prolongando el juicio la Corona durante varios años sin pronunciarse sobre el mismo, sin resolverlo. Una vez que Cortés fue sometido a residencia por el primer juez Luis Ponce de León, en julio de 1526, jamás volvió a tener el gobierno de la Nueva España; el gobierno se encargó a la primera audiencia, de triste memoria, presidida precisamente por Nuño de Guz- mán; después el gobierno pasó a la segunda audiencia y, en 1535, al virrey junto con la propia audiencia. ${ }^{8}$

$\mathrm{Al}$ referirse el autor a los asuntos que competía conocer, en jurisdicción, a alcaldes ordinarios y alcaldes mayores, dice que tocaba "al alcalde mayor impartir la justicia criminal, y los ordinarios se encargaban de la civil" (p. 122). Esto no es exacto, pues tanto los alcaldes ordinarios como los alcaldes mayores conocen de la materia civil y de la criminal. La administración de justicia novohispana es muy compleja, pero en principio podemos decir que los alcaldes mayores constituyen en algunos casos una especie de segunda instancia de las causas conocidas y resueltas por los ordinarios, aunque también conocen negocios en primera instancia; por otro lado, la función de los alcaldes mayores es más administrativa que judicial. ${ }^{9}$

Otro punto en que disentimos con el autor es el referente a la creación de la alcaldía mayor de Aguascalientes. El Dr.

8 José Luis Martínez, Hernán Cortés, México, Unam y Fondo de Cultura Económica, 1990.

9 Del Arenal Fenochio, Jaime. "Instituciones Judiciales de la Nueva España", en Revista de Investigaciones Jurídicas, núm. 22, Escuela Libre de Derecho. México, 1998; y Jesús Antonio De la Torre Rangel, Lecciones de Historia del Derecho Mexicano. México, Universidad Autónoma de Aguascalientes. Aguascalientes, 1997. 
Gutiérrez considera incorrecto lo que dicen Agustín R. González y Jesús Bernal Sánchez en el sentido de que en 1611 se le concedió a Aguascalientes la categoría de alcaldía mayor, porque "desde su fundación fue villa con cabildo y categoría de alcaldía mayor" (p. 114). Consideramos que llevan razón González y Bernal Sánchez, aunque quizás no en el año que mencionan -Beatriz Rojas dice que se creó entre 1611 y 1619-. ${ }^{10}$ Afirmamos esto porque de la cédula de fundación de Aguascalientes sólo se desprende la creación de una villa con sus autoridades que forman el ayuntamiento; se crea nada más una autoridad local con jurisdicción local; las alcaldías mayores son gobiernos regionales cuya jurisdicción comprende varios pueblos, lugares y hasta villas. Por las circunstancias de creación de la villa de la Asunción, nos parece que no estaban dadas las circunstancias para conferirle jurisdicción y gobierno regional. En lo que puede tener razón el Dr. Gutiérrez es que en la primera década del siglo XVII ya funcionara como alcaidía mayor.

$\mathrm{Al}$ referirse el autor a la cédula de fundación de Aguascalientes de 22 de octubre de 1575, dada por el presidente de la audiencia de Nueva Galicia, en representación del rey Felipe II, dice que en opinión de Ángel Tiscareño "nunca tuvo confirmación del rey" (p. 108). Nosotros decimos que no requería de tal confirmación, porque la audiencia tenía facultades suficientes para otorgar, como lo hizo, la real cédula de fundación de Aguascalientes, la que, como todo acto de gobierno en la Nueva España, se expidió en representación del rey. No fue sino hasta la ordenanza del 10 de abril de 1629 de Felipe IV, en donde se previno que en adelante, los virreyes, las audiencias, gobernadores y demás ministros de Indias, no podía ya dar títulos de ciudades ni de villas a ninguno de los pueblos o lugares de españoles ni de indios, pues en lo sucesivo era todo facultad exclusiva del monarca. ${ }^{11}$

El Dr. Gutiérrez sostiene como hipótesis que San Marcos no tuvo un nacimiento validado jurídicamente como pueblo o "congrega", sino sólo como arrabal o barrio de Aguascalientes (págs. 124-125). Sin embargo, poco más adelante, contradiciendo su afirmación anterior dice: "San Marcos continuó creciendo como la Villa; y como congrega india contó con autoridades autónomas..." (p. 127).

10 Beatriz Rojas, Las instituciones de gobierno y la élite local. Aguascalientes del siglo XVII hasta la Independencia, México, El Colegio de Michoacán e Instituto Mora, 1998, p. 187.

11 Jesús Antonio De la Torre Rangel, Notas histórico-jurídicas sobre la fundación de Aguascalientes, México, Ed. Jus, 1990. págs. 43-47. 
$\mathrm{El}$ autor dice textualmente: "La historia de Aguascalientes, en el siglo XIX, contiene muchas sorpresas importantes. La subdelegación transitó de municipio a estado, en 1835, con una interrupción breve de su soberanía." Con todo respeto dỉgo que esta afirmación es muy simplista y cae en la falsedad. Jurídicamente es complejísimo el transitar del Aguascalientes subdelegación de intendencia hasta el Aguascalientes estado de la república federal; antes fue partido del estado de Zacatecas, territorio de la federación, y departamento de repúblicas centralistas en dos períodos. Sólo se consolida como estado hasta 1857.

Para terminar estos apuntamientos críticos, quiero expresar mi disidencia con relación a una afirmación del autor. Él se pregunta: “¿pueden considerarse pioneros de la evangelización neogallega los eclesiásticos que acompañaron a Nuño de Guzmán?", el conquistador de Nueva Galicia. El Dr. Gutiérrez dice que si bien fueron más capellanes de la hueste de Guzmán que misioneros, sí se les puede considerar como pioneros de la evangelización por el contacto -aunque pococon algunos indígenas (p. 49). Desde mi punto de vista, en virtud de las caracte- rísticas de la conquista de Guzmán, cruel, despiadada y sanguinaria, auténtico contrasentido del Evangelio, sus capellanes no pueden ser precursores de evangelización, a menos que se hubiesen opuesto a sus atrocidades y precisamente en nombre del Evangelio.

\section{PARA TERMINAR}

El libro del Dr. José Antonio Gutiérrez es, pues, muy sugerente y lleno de datos importantes, producto del trabajo de muchos años. Damos la bienvenida con gusto a su publicación y felicitamos al autor por ello.

Nos quedamos a la espera de las otras obras que el autor ya ha anunciado sobre la historia de la Iglesia aguascalenteña, que tiene ya en preparación.

También esperamos que otros historiadores trabajen como el Dr. Gutiérrez y la doctora Yolanda Padilla, la rica y extensa historia de nuestra iglesia diocesana. Por lo pronto, insisto, nos quedamos a la espera de las obras ya anunciadas del autor del libro que comentamos y, de otra, sobre esta temática, que está preparando el padre Ricardo Martín del Campo, actual rector de la Universidad Pontificia. 중 